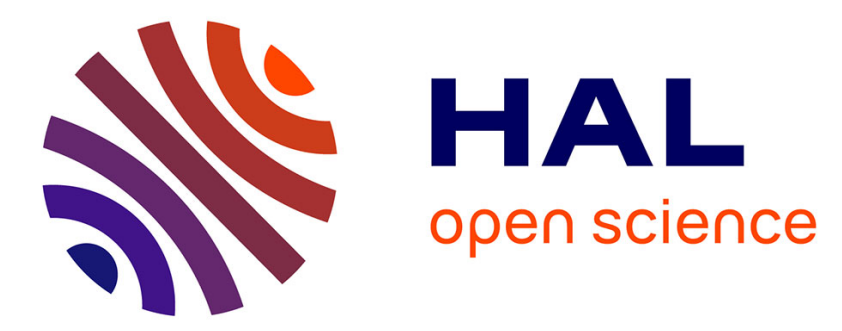

\title{
Determination of L-X-ray line emission intensities in the decay of Cm-244 with a metallic magnetic calorimeter
}

\author{
Riham Mariam, Matias Rodrigues, Martin Loidl
}

\section{To cite this version:}

Riham Mariam, Matias Rodrigues, Martin Loidl. Determination of L-X-ray line emission intensities in the decay of Cm-244 with a metallic magnetic calorimeter. Nuclear Instruments and Methods in Physics Research Section A: Accelerators, Spectrometers, Detectors and Associated Equipment, 2020, 954, pp.162066. 10.1016/j.nima.2019.04.020 . hal-03489693

\section{HAL Id: hal-03489693 https://hal.science/hal-03489693}

Submitted on 4 Jan 2022

HAL is a multi-disciplinary open access archive for the deposit and dissemination of scientific research documents, whether they are published or not. The documents may come from teaching and research institutions in France or abroad, or from public or private research centers.
L'archive ouverte pluridisciplinaire HAL, est destinée au dépôt et à la diffusion de documents scientifiques de niveau recherche, publiés ou non, émanant des établissements d'enseignement et de recherche français ou étrangers, des laboratoires publics ou privés. 


\section{Determination of L-X-ray line emission intensities in the decay of Cm-244 with a metallic magnetic calorimeter Riham Mariam, Matias Rodrigues, Martin Loidl}

CEA, LIST, Laboratoire National Henri Becquerel (LNE-LNHB), CEA-Saclay, 91191 Gif sur Yvette

\section{Cedex, France}

\section{Keys words: Metallic Magnetic Calorimeter (MMC), Actinide, X-ray spectrometry}

Abstract: Emissions of L-X-rays by actinides are quite intense due to the large internal conversion coefficients of the gamma transitions. These emissions can be beneficial for the quantitative analysis of actinides by photon spectrometry, however the L X-rays emitted by radionuclides are generally not well known. Several studies explored the L-X-ray regions of actinides and measured total intensities of L-Xray groups, partially with large uncertainties up to $10 \%$. However, they cannot resolve the individual LX-ray lines due to the limited energy resolution (of the order of $200 \mathrm{eV}$ (FWHM) at $25 \mathrm{keV}$ ) of the semiconductor detectors. The present work shows and discusses the measurement of individual L-X-ray line emission intensities emitted by $\mathrm{Cm}-244$ using an ultra-high-resolution spectrometer. The used spectrometer is a Metallic Magnetic Calorimeter (MMC) conceived for photon spectrometry below 100 $\mathrm{keV}$ with an energy resolution of $37 \mathrm{eV}$ at $20 \mathrm{keV}$ and a nearly constant efficiency over the L X-ray energy range. A high-resolution spectrum with a counting statistics of $4.6 \times 10^{6}$ counts was obtained. The spectrum processing allowed to determine the individual emission intensities of $30 \mathrm{~L}$-X-ray lines despite the narrow energy spacing.

\section{Introduction}

Most actinides decay to many nuclear excited states. Some of the related gamma transitions have large internal conversion coefficients (ICCs), which lead to intense emission of X-ray photons during the atomic rearrangement. The detection of these photons could be used to analyze samples with mixed actinides. However, the knowledge of these emission intensities of L-X-rays is limited in particular for 
Cm-244: there is only one measurement with large uncertainties [1]. According to the literature, the knowledge of these emissions concerns only the L-X-ray groups, and it suffers from large uncertainties due to the limited resolution of semi-conductor detectors and to the K-edge discontinuity in the Ge detector detection efficiency, in the L-X-ray energy range [2][3]. Cm-244 decays with $76.7 \%$ probability by alpha emission to the first excited state of Pu-240 at $42 \mathrm{keV}$. The $\gamma$ transition ( $E_{2}$ electromagnetic transition) is highly converted, involving mainly the L-shell with an ICC $\alpha_{\mathrm{L}}=658$ (13). In addition, with a fluorescence yield $\omega_{L}=0.521$ (20) [2], this $\gamma$ transition leads to intense X-ray emissions below $25 \mathrm{keV}$. The L-X-ray spectrum is very complex because of the many possible transitions to fill the hole in the atomic inner subshells $\left(L_{1}, L_{2}, L_{3}\right)$ of the daughter. According to the ICC of each sub-shell, there are $0.442(18), 12.3(5)$ and 10.62(44) primary vacancies per 100 decays created respectively in the L1, L2 and L3 subshells. In order to recover the electronic ground state, different atomic radiative and non-radiative processes can take place depending on their probabilities. An electron from an outer subshell can fill the vacancy with an emission of X-ray photon or electron from an outer shell, called diagram line emission : $L_{i}-Y_{j}(\mathrm{i}=1,2,3 ; \mathrm{j}=1 . .7 ; \mathrm{Y}=\mathrm{M}, \mathrm{N}, \mathrm{O}, \mathrm{P})$. However, the vacancy created by the IC in $L_{i}$ can excite an outer subshell which has the same quantum number $L_{j}(j>i)$. This transition called $\mathbf{C o s t e r - K r o n i g}(\mathbf{C K}$, a radiationless transition) ejects an electron from an outer subshell $Y_{k}(\mathrm{Y}=\mathrm{M}, \mathrm{N}, \mathrm{O}, \mathrm{P})$. The $L_{i^{-}} L_{j}$ transition is defined by the probability of CK $f_{i j}\left(\mathrm{Cm}-244: f_{12}=0.03, f_{23}=0.214, f_{13}=0.68\right.$ : respectively $\mathrm{L}_{1} \mathrm{~L}_{2}, \mathrm{~L}_{2} \mathrm{~L}_{3}$ and $\mathrm{L}_{1} \mathrm{~L}_{3}$ [4]). This work presents a measurement of the L-X-ray line intensities using a high resolution spectrometer developed at CEA LNHB. This spectrometer called SMX3 consists in an MMC detector dedicated to photon spectrometry below $100 \mathrm{keV}$. The basic idea of a cryogenic detector is the measurement of an energy deposit as a temperature rise in the detector. An MMC consists of a metallic absorber strongly thermally coupled to a paramagnetic sensor, which, located in a weak magnetic field, has a temperature dependent magnetization. The photon with an energy $E$ interacting in the metallic absorber, characterized by a heat capacity $C$, results a temperature change $\Delta T=E / C$. The temperature variation in the absorber is converted to a magnetization variation $\Delta M(T)$ by the sensor. The 
magnetization change generates a flux change in a flux transformer magnetically coupled to a Superconducting Quantum Interference Device (SQUID) [5]. The metallic absorber used in SMX3 consists in a double layer of $\mathrm{Au}$ and $\mathrm{Ag}$ offering a constant and smooth intrinsic efficiency (> 98\%) below $25 \mathrm{keV}$, unattainable with an absorber with a single layer of Au or Ag [6]. An electroplated source of Cm-244 with an activity of $71.54(15) \mathrm{kBq}$ prepared at LNHB, thin enough to avoid self-absorption, was integrated with SMX3. A tungsten collimator is used to define the solid angle and also to avoid photon interaction in the read-out chip. The alpha particles and the electrons from the Cm-244 decay are blocked using a beryllium window which allows transmitting $61.6 \%$ to $96.3 \%$ of the M-X-rays ranging from $2.2 \mathrm{keV}$ to $5.92 \mathrm{keV}$ and $>99.5 \%$ of the $\mathrm{L} \mathrm{X-rays} \mathrm{ranging} \mathrm{from} 12$ to $22 \mathrm{keV}$.

\section{Spectrum processing and discussion}

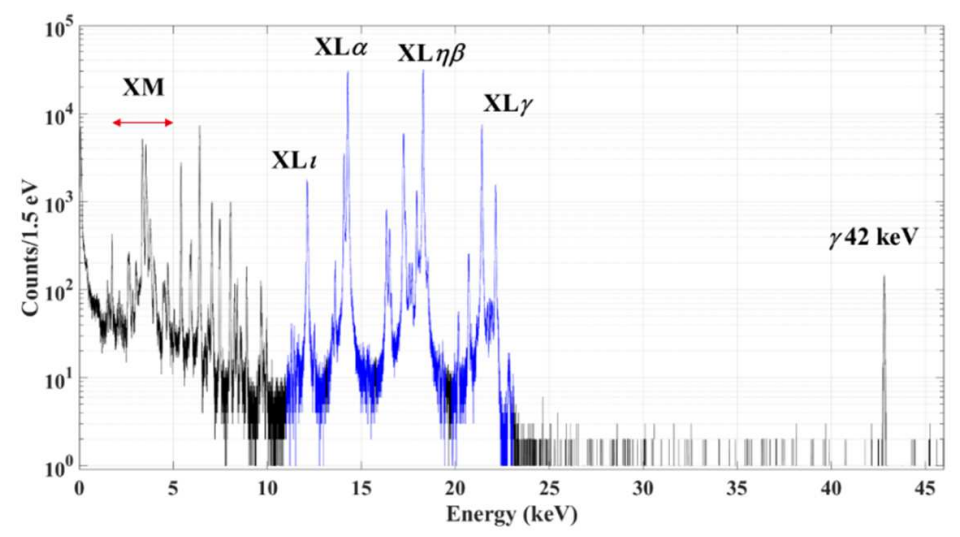

Figure 1 Photon emission spectrum in the decay of $\mathrm{Cm}-244$

SMX3 was cooled down to $10 \mathrm{mK}$ using a dilution refrigerator. The output voltage of the SQUID electronics was digitized continuously during 10 days with an 16-bit resolution acquisition card at a sampling frequency of $250 \mathrm{kHz}$ and stored on a hard disk. This signal was analyzed offline following the different steps described in [7] to obtain the spectrum of Cm-244 presented in the figure 1. This spectrum shows the different regions of the L-X-rays which were deconvoluted using the Colegram software [8]; the X-ray lines were fitted using a Voight function (convolution of a Gaussian and a Lorentzian functions) with a fixed Lorentzian width taken from [9]. The FWHM of the Gaussian was determined on the X-ray 
fluorescence lines emitted by the source and detector holders ( $\mathrm{Fe}, \mathrm{Ni}, \mathrm{Cu}, \mathrm{Mn}$ ) and at the $42 \mathrm{keV} \gamma$ line. A second degree polynomial function was built to evaluate the FWHM of the Gaussian depending on the energy. The FWHM ranges from $32.43 \mathrm{eV}$ at $6 \mathrm{keV}$ to $37 \mathrm{eV}$ at $20 \mathrm{keV}$. The background was fitted using an exponential function. The high statistics of $4.610^{6}$ counts and the high energy resolution give access to the complex L-X-ray structure. Figure 2 shows the different L X-ray groups $(\mathrm{XL} \imath, \mathrm{XL} \alpha, \mathrm{XL} \beta, \mathrm{XL} \eta$, $\mathrm{XL} \gamma$ ); which have been analyzed separately using Colegram. The spectrum shows different physical processes that take place after the IC of the $\gamma$ transition (mainly $E_{2}$ electromagnetic at $42 \mathrm{keV}$ ). The daughter atom $\mathrm{Pu}-240$ recovers the electronic configuration by filling the vacancy created by the conversion electron ejection in different processes. Therefore, the L-X-ray spectrum of the $\mathrm{Cm}-244$ is very complex to deconvolute. A diagram line $L_{i}-Y_{j}(\mathrm{i}=1,2,3 ; \mathrm{j}=1 . .7 ; \mathrm{Y}=\mathrm{M}, \mathrm{N}, \mathrm{O}, \mathrm{P})$ occurs when an outer electron from $Y_{j}$ fills the $L_{i}$ vacancy emitting an L-X-ray with an energy equal to the difference between the binding energies of the subshells $L_{i}-Y_{j}$. For example, $\mathrm{XL} l$ in figure 2 shows the $\mathrm{L}_{l}: L_{3}-$ $M_{l}\left(2 \mathrm{p}_{3 / 2}-3 \mathrm{~s}\right)$ diagram line fitted using a Voight in green. The spectrum shows also intense satellite structure, due to multiple vacancy states of the atom during the recovery of the ground state. The multiple vacancies are mainly produced by three processes: Shake-off, Shake-up or Coster-Kronig [10]. Because of the intense $\mathrm{CK}$ transitions $f_{23}$ and $f_{13}$, the satellite effect is mainly produced when the transition corresponds to $L_{3}-Y_{j}$. For example, the above mentioned $L l: L_{3}-M_{l}\left(2 \mathrm{p}_{3 / 2}-3 \mathrm{~s}\right)$ emission has a satellite line due to the high CK probability $f_{13}$ (small probability of Shake-off, Shake-up [11]). So, the primary vacancy is created by IC in the $L_{1}$ moved by CK to the $L_{3}$. An electron is emitted from $M_{5}$ during the transition $L_{1} L_{3}$ (high emission probability from $M_{5}$ compared to the other $Y_{k}$ subshell transitions according to [12]). The region $\mathrm{XL} \eta \beta$ shows an intense satellite structure at the $\mathrm{L} \beta_{2}: L_{3}-N_{5}$. It presents a different energy shift compared to the satellite structure of the $L \imath: L_{3}-M_{l}$ (figure 2). Due to the different $j-j$ coupling of the final two hole states $L_{3} M_{4}$ and $L_{3} M_{5}$ respectively in the transitions $L_{1} L_{3} M_{1}$ and $L_{1} L_{3} N_{5}$, the Hamiltonians of these transitions have a different Coulomb potential and different $j$-j element. 

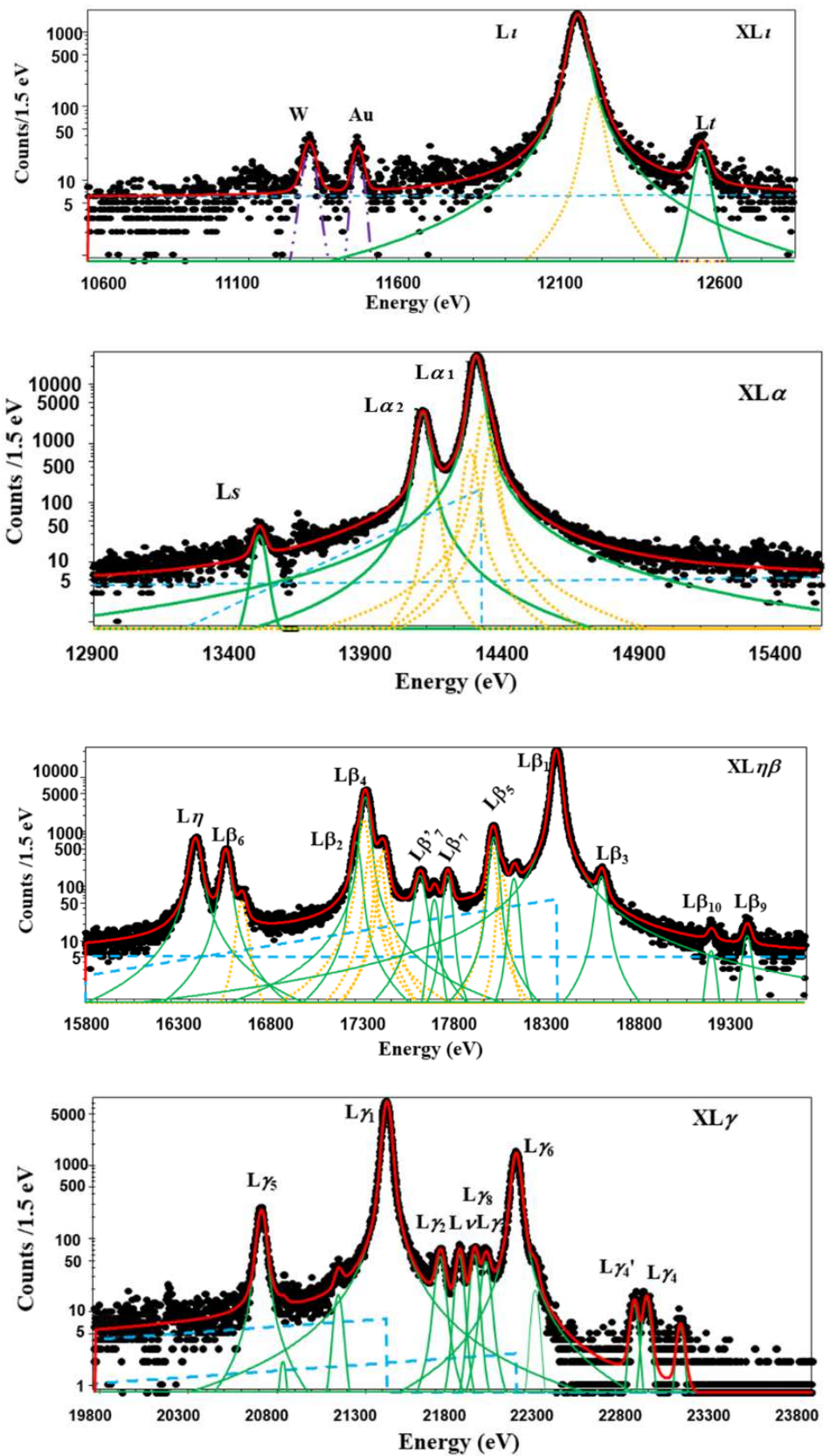

Figure 2 Different regions of L-X-rays deconvoluted using Colegram: (Green solid line) Diagram line transition: Atomic configuration in a single vacancy state, (Yellow dashed line) Satellite structure: CosterKronig transition; when the atomic configuration is in a multiple vacancies state; (Blue dashed line) Background; (Purple dash--dotted line) X-ray emission: Au and W fluorescence.

Thus resolving the Schrödinger equation the energy will be different [11,12]. The $L_{2}-Y_{j}$ transitions can present a satellite structure due to the shake-off process or a CK transition lead by $f_{12}$. However, in the decay of Cm-244 this type of satellite cannot be observed due to the weak shift of energy with respect to the diagram line. Therefore, satellite structures for $L_{2}-Y_{j}$ and $L_{1}-Y_{j}$ X-ray transitions due to the CK 
processes are not observed. Most of the L-X-ray emissions range from 11 to $24 \mathrm{keV}$. However, an L-Xray emission was detected at $5 \mathrm{keV}$ in the region of M-X-rays, the transition $L_{1}-L_{3}$ that was never observed before shown in figure 3. It was also fitted using a Voigt function.

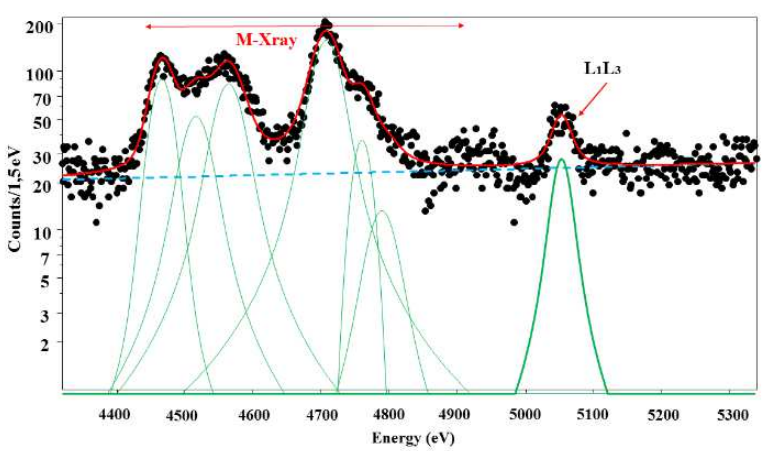

Figure 3 Region of M-X-rays: (Green line) Diagram line transition, (Green solid line) the transition $L_{1}-L_{3}$ (Blue dashed line) Background

After this processing of each X-ray region, the number of absorbed photons for each emission was determined. The intrinsic efficiency of SMX3 presents a slight variation between $\sim 99.5 \%$ and $99.7 \%$ below $25 \mathrm{keV}$. The effect of this efficiency variation on the emission intensities is taken into account and its uncertainty is also accounted for in the estimation of the intensity uncertainty. Finally, the number of absorbed photons is normalized by the total number of absorbed photon in the L-X-ray region.

\section{Decay data for $\mathbf{C m}-244$}

Table 2 shows the relative intensities of the measured transitions that lead to an L-X-ray line in the decay of Cm-244, presented in two different nomenclatures: IUPAC and Siegbahn. Using the measured L-X-ray lines, we determine the L-X-ray group intensities relatively to the $\mathrm{XL} \eta \beta$ in order to compare to the relative intensities measured in [14]; a good agreement is observed. In addition we compare the relative line intensities measured with SMX3 to the intensities measured in [1]. Authors in [1] measured the L-Xray lines intensities using the coincidence technique based on a semi-conductor detector; the uncertainties shown in this work are dominated by the statistical uncertainties. We determine the intensities of all the emissions from the same $L_{i}$ subshell, relative to the total intensity of the L-X-ray region. This is compared 
to the same value but determined theoretically from the CK probability and the fluorescence yield of each resolution and accuracy X-ray line intensities for metrological applications and fundamental physics.

Table 1

\begin{tabular}{ccc}
\hline $\begin{array}{c}\text { Intensity } \\
\text { relative } \\
\text { to XL }\end{array}$ & SMX3 & Theory \\
\hline $\boldsymbol{I}_{\mathbf{L 1}}$ & $0.006622(6)$ & $0.0076(26)$ \\
\hline $\boldsymbol{I}_{\mathbf{L} 2}$ & $0.4776(9)$ & $0.48(9)$ \\
\hline $\boldsymbol{I}_{\mathbf{L 3}}$ & $0.5151(8)$ & $0.51(10)$ \\
\hline
\end{tabular}

\section{Table 2}

\begin{tabular}{|c|c|c|c|c|c|c|c|c|}
\hline & \multicolumn{2}{|c|}{ Transition } & \multirow[t]{2}{*}{ Energy (eV) } & \multirow[t]{2}{*}{ Width (eV) } & \multirow{2}{*}{$\begin{array}{c}\text { Intensity relative } \\
\text { to }\end{array}$} & \multirow{2}{*}{$\begin{array}{c}\text { Intensity } \\
{[1]}\end{array}$} & \multirow{2}{*}{$\begin{array}{c}\text { Group } \\
\text { Intensity } \\
\text { SMX3 }\end{array}$} & \multirow{2}{*}{ 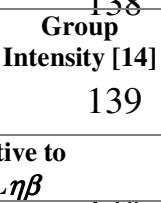 } \\
\hline & IUPAC & Siegbahn & & & & & & \\
\hline & $\mathbf{L}_{1}-\mathbf{L}_{3}$ & & 5.047 & 21.32 & $0.0268(12)$ & not detected & & 140 \\
\hline \multirow[t]{2}{*}{$\mathrm{XL} t$} & $\mathbf{L}_{3}-\mathbf{M}_{1}$ & $\mathbf{L} \boldsymbol{l}$ & 12124 & 26,82 & $2.569(12)$ & \multirow{2}{*}{$\begin{array}{c}\text { not } \\
\text { deconvoluted }\end{array}$} & \multirow[t]{2}{*}{$5,441(30)$} & \multirow[t]{2}{*}{$5,3(8)$} \\
\hline & $\mathrm{L}_{3}-\mathrm{M}_{2}$ & $\mathbf{L} t$ & 12510 & 22,82 & $0.0306(9)$ & & & \\
\hline \multirow[t]{3}{*}{$\mathrm{XL} \alpha$} & $\mathbf{L}_{3}-\mathbf{M}_{3}$ & $\mathbf{L s}$ & 13497 & 15.82 & $0.0313(9)$ & \multirow{3}{*}{$\begin{array}{c}\text { not } \\
\text { deconvoluted }\end{array}$} & \multirow[t]{3}{*}{$80,05(36)$} & \multirow[t]{3}{*}{$72(7) 41$} \\
\hline & $\mathbf{L}_{3}-\mathbf{M}_{4}$ & $\mathbf{L} \alpha_{2}$ & 14085.4 & 11.22 & $3.655(17)$ & & & \\
\hline & $\mathbf{L}_{3}-\mathbf{M}_{5}$ & $\mathbf{L} \alpha_{1}$ & 14280.9 & 11.02 & $34.56(10)$ & & & \\
\hline & $\mathbf{L}_{2}-\mathbf{M}_{1}$ & $\mathbf{L} \eta$ & 16333 & 29.5 & $1.139(8)$ & $1.171(31)$ & \multirow[t]{12}{*}{100} & \multirow{4}{*}{${ }^{100} 42$} \\
\hline \multirow{11}{*}{$\mathrm{XL} \beta$} & $\mathrm{L}_{3}-\mathrm{N}_{1}$ & $\mathbf{L} \beta_{6}$ & 16498 & 19.52 & $0.6351(50)$ & $0.574(11)$ & & \\
\hline & $\mathbf{L}_{3}-\mathbf{N}_{4,5}$ & $\mathbf{L} \beta_{2}$ & 17259 & 11.82 & $8.265(30)$ & not detected & & \\
\hline & $\mathbf{L}_{1}-\mathbf{M}_{2}$ & $\mathbf{L} \beta_{4}$ & 17557 & 28.5 & $0.2233(27)$ & $0.528(34)$ & & \\
\hline & $\mathbf{L}_{3}-\mathbf{N}_{7}$ & $\mathbf{L} \beta_{7^{\prime}}^{\prime}$ & 17635.9 & 7.82 & $0.0537(12)$ & not detected & & \multirow[t]{3}{*}{143} \\
\hline & $\mathrm{L}_{3}-\mathrm{O}_{1}$ & $\mathbf{L} \beta_{7}$ & 17707 & 7.82 & $0.1457(21)$ & not detected & & \\
\hline & $\mathrm{L}_{3}-\mathrm{O}_{5}$ & $L \beta_{5}$ & 17955 & 7.82 & $1.434(8)$ & not detected & & \\
\hline & $\mathbf{L}_{3}-\mathbf{P}_{1}$ & & 18067.8 & 7.82 & $0.1303(20)$ & not detected & & \multirow[t]{3}{*}{144} \\
\hline & $\mathbf{L}_{2}-\mathbf{M}_{4}$ & $\mathbf{L} \beta_{1}$ & 18296.2 & 13.9 & 35.54 (12) & $35.94(34)$ & & \\
\hline & $\mathbf{L}_{1}-\mathbf{M}_{3}$ & $L \beta_{3}$ & 18541 & 21.5 & $0.1939(25)$ & $0.264(11)$ & & \\
\hline & $\mathbf{L}_{1}-\mathbf{M}_{4}$ & $\mathbf{L} \beta_{10}$ & 19134 & 16.9 & $0.00763(42)$ & $0.0367(11)$ & & \multirow{2}{*}{145} \\
\hline & $\mathbf{L}_{1}-\mathbf{M}_{5}$ & $\mathbf{L} \beta_{9}$ & 19329 & 16.7 & $0.0146(6)$ & $0.0264(23)$ & & \\
\hline \multirow[t]{12}{*}{$\mathrm{XL} \gamma$} & $\mathrm{L}_{2}-\mathrm{N}_{1}$ & $\mathbf{L} \boldsymbol{\xi}$ & 20707 & 22.2 & $0.3142(34)$ & $0.321(11)$ & \multirow[t]{12}{*}{$23,75(11)$} & $22,4(23)$ \\
\hline & $\mathrm{L}_{2}-\mathrm{N}_{3}$ & & 21143 & 17.5 & $0.0208(7)$ & not detected & & \multirow{7}{*}{147} \\
\hline & $\mathrm{L}_{2}-\mathrm{N}_{4}$ & $\mathbf{L} \boldsymbol{x}$ & 21420.4 & 14.5 & $8.704(37)$ & $8.70(7)$ & & \\
\hline & $\mathbf{L}_{1}-\mathbf{N}_{2}$ & $\mathbf{L} \gamma_{2}$ & 21723.2 & 22.5 & $0.0751(16)$ & not detected & & \\
\hline & $\mathbf{L}_{2}-\mathrm{N}_{6}$ & $\mathbf{L} \boldsymbol{v}$ & 21832.5 & 10.5 & $0.0621(13)$ & not detected & & \\
\hline & $\mathrm{L}_{2}-\mathrm{O}_{1}$ & $\mathbf{L} \gamma$ & 21917.4 & 10.5 & $0.0639(13)$ & not detected & & \\
\hline & $\mathbf{L}_{1}-\mathbf{N}_{3}$ & $\mathbf{L} \mathfrak{z}$ & 21983.3 & 20.5 & $0.0615(13)$ & not detected & & \\
\hline & $\mathrm{L}_{2}-\mathrm{O}_{4}$ & $L x_{6}$ & 22152.4 & 19.52 & $2.006(13)$ & $2.044(23)$ & & \\
\hline & $\mathrm{L}_{1}-\mathrm{N}_{4}$ & & 22259 & 10.5 & & & & \multirow[t]{4}{*}{148} \\
\hline & $\mathrm{L}_{1}-\mathrm{O}_{2}$ & $\mathbf{L} \boldsymbol{y}_{4}^{\prime}$ & 22821 & 13.5 & $0.0145(6)$ & $0.0367(23)$ & & \\
\hline & $\mathrm{L}_{1}-\mathrm{O}_{3}$ & $\mathbf{L} \boldsymbol{\mu}$ & 22891 & 13.5 & $0.0171(6)$ & not detected & & \\
\hline & $\mathbf{L}_{1}-\mathbf{P}_{1}$ & & 23075 & 13.5 & $0.00689(38)$ & not detected & & \\
\hline
\end{tabular}




\section{References}

[1] P. N. Johnston and P. A. Burns, "Absolute L X-ray intensities in the decays of ${ }^{230} \mathrm{Th},{ }^{234} \mathrm{U},{ }^{238} \mathrm{Pu}$ and $244 \mathrm{Cm}$," Nucl. Instr. Meth A 361, 229-239, 1995.

[2] M.-M. Bé and Bureau International des Poids et Mesures, Eds., Table of radionuclides. Vol. 6: A=22 to 242. Sèvres: BIPM, 2011.

[3] M. C. Lépy, J. Plagnard, and L. Ferreux, "Measurement of ${ }^{241}$ Am L X-ray emission probabilities," Appl. Rad. Isot. 66, no. 6-7, pp. 715-721, Jun. 2008.

[4] J. L. Campbell, "Fluorescence yields and Coster-Kronig probabilities for the atomic L subshells," Atomic Data and Nuclear Data Tables, vol. 85, no. 2, pp. 291-315, Nov. 2003.

[5] A. Fleischmann, C. Enss and G. M. Seidel, in Cryogenic Particle Detection, Topics Appl. Phys. 99, C. Enss (Ed.), Springer, Berlin/ Heidelberg (2005) 151-216.

[6] M. Rodrigues, R. Mariam, and M. Loidl, "A metallic magnetic calorimeter dedicated to the spectrometry of L X-rays emitted by actinides," EPJ Web of Conferences, vol. 146, p. 10012, 2017.

[7] R. Mariam, M. Rodrigues, and M. Loidl, "Full-Energy Peak Efficiency Calibration of a Metallic Magnetic Calorimeter Detector for Photon Spectrometry Below 100 keV," J. Low Temp. Phys, June 2018.

[8] H. Ruellan, M. C. Lépy, M. Etcheverry, J. Plagnard, and J. Morel, "A new spectra processing code applied to the analysis of ${ }^{235} \mathrm{U}$ and ${ }^{238} \mathrm{U}$ in the 60 to $200 \mathrm{keV}$ energy range," Nucl. Instr. Meth A 369, no. 2, pp. 651-656, Feb. 1996.

[9] J. L. Campbell and T. Papp, "WIDTHS OF THE ATOMIC K-N7 LEVELS,” Atomic Data and Nuclear Data Tables, vol. 77, no. 1, pp. 1-56, Jan. 2001.

[10] M. Rodrigues and M. Loidl, "L X-ray satellite effects on the determination of photon emission intensities of radionuclides,” Appl. Rad. Isot. 109, pp. 570-575, Mar. 2016.

[11] T. Mukoyama, "Electron shake probabilities of heavy elements as a result of M-shell vacancy production: Shake probabilities as a result of M-shell vacancy production," X-Ray Spectrometry, vol. 44, no. 1, pp. 7-12, Jan. 2015.

[12] M. H. Chen, B. Crasemann, and H. Mark, "Relativistic radiationless transition probabilities for atomic K- and L-shells," Atomic Data and Nuclear Data Tables, vol. 24, no. 1, pp. 13-37, Jul. 1979.

[13] F. Parente, M. H. Chen, B. Crasemann, and H. Mark, "L x-ray satellite energies," Atomic Data and Nuclear Data Tables, vol. 26, no. 5, pp. 383-466, Sep. 1981.

[14] Yu.S.Popov, I.B.Makarov, D.Kh.Srurov, E.A.Erin, "M-and L-X-rays emission of actinides," vol. Radiokhimiya 32, 2, pp. 2-450, 1990.

[15] M. C. Lépy, B. Duchemin, and J. Morel, "Comparison of experimental and theoretical L X - ray emission probabilities of ${ }^{241} \mathrm{Am},{ }^{239} \mathrm{Pu}$ and ${ }^{240} \mathrm{Pu}, "$ Nucl. Instr. Meth. A 353, 10-15, Dec. 1994. 